\section{Statin therapy now more common than steroids in clinical practice}

Dear Editor,

In the recent article from Ozen et $a l^{1}$, the authors found increased risk of diabetes mellitus (DM) in patients with rheumatoid arthritis (RA) compared with normal US adult population.

The authors have also reported increased risk of DM in patients with RA who took glucocorticoids (GCs) and statin therapy. Surprisingly, the HR of diabetes has been found to be higher in the statin group than in the steroid group. It is important to know the duration of exposure to steroids in patients with RA . Not all patients may be exposed to steroids for prolonged period. The authors may comment on the duration of steroids in various patients.

While the concomitant use of GC did not alter DM risk reduction with HCQ, the authors have also reported DM risk reduction with concomitant use of HCQ and statin therapy. The authors have mentioned the risk of incident diabetes by steroid dose, HCQ dose, and duration and concomitant GC use in a tabular form (table 4, page no. 5) but similar information is missing for concomitant use of statin and HCQ. We request the authors to throw more light on this.

In our study, 'Efficacy and safety of fixed dose combination of atorvastatin and hydroxychloroquine: a randomized, doubleblind comparison with atorvastatin alone among Indian patients with dyslipidemia', we compared the efficacy and safety of atorvastatin $(10 \mathrm{mg})+$ hydroxychloroquine $(200 \mathrm{mg})$ fixed-dose combination tablets in comparison with atorvastatin $(10 \mathrm{mg})$ alone in treatment of dyslipidaemia for 6 months and found in exploratory analysis that $15 \%$ patients with prediabetic dyslipidaemia from the monotherapy group and $2 \%$ from the combination group developed diabetes. ${ }^{2}$

Other observational studies have also suggested the potential benefit of hydroxychloroquine in attenuating the risk of diabetes in patients with RA. A population-based cohort study in patients with systemic lupus erythematosus ${ }^{3}{ }^{4}$ demonstrated an increased risk of DM with high dose of GC which was decreased by concomitant use of HCQ in a dose-dependent manner. $^{5}$
It is important to note that in comparison with GC, which may often be used intermittently for short period, statin therapy is used for long term to reduce cardiovascular risk. Hence, it is important to know the risk of diabetes due to statin exposure in patients with RA and the preventive role of HCQ in the same.

\section{Anil Pareek, ${ }^{1}$ Nitin Chandurkar ${ }^{2}$}

${ }^{1}$ Medical Affairs and Clinical Research, Ipca Laboratories Ltd, Mumbai, India ${ }^{2}$ Clinical Research and Development, Ipca Laboratories, Mumbai, India

Correspondence to Dr Anil Pareek, Medical Affairs and Clinical Research, Ipca Laboratories Ltd, Mumbai, 400067 India; anil.pareek@ipca.com

Acknowledgements Authors would like to acknowledge the efforts of Kumar Naidu and Shruti Dharmadhikari for their efforts in initial drafting of this manuscript.

Contributors AP and NC were involved in drafting or revising this manuscript critically. Both the authors approved the final version to be published.

Competing interests AP and NC report being employees of Ipca Laboratories in India, a company that manufactures and sells antidiabetic drugs.

Provenance and peer review Not commissioned; internally peer reviewed.

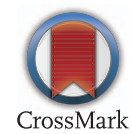

To cite Pareek A, Chandurkar N. Ann Rheum Dis 2017;76:e18.

Received 22 November 2016

Accepted 1 December 2016

Published Online First 22 December 2016

Ann Rheum Dis 2017;76:e18.

\section{REFERENCES}

1 Ozen G, Pedro S, Holmqvist ME, et al. Risk of diabetes mellitus associated with disease-modifying antirheumatic drugs and statins in rheumatoid arthritis. Ann Rheum Dis 2017:76:848-54.

2 Pareek A, Chandurkar N, Thulaseedharan NK, et al. Efficacy and safety of fixed dose combination of atorvastatin and hydroxychloroquine: a randomized, double-blind comparison with atorvastatin alone among Indian patients with dyslipidemia. CMRO 2015;31:2105-17.

3 Bili A, Sartorius JA, Kirchner HL, et al. Hydroxychloroquine use and decreased risk of diabetes in rheumatoid arthritis patients. I Clin Rheumatol 2011;7:115-20.

4 Wasko MC, Hubert HB, Lingala VB, et al. Hydroxychloroquine and risk of diabetes in patients with rheumatoid arthritis. JAMA 2007;298:187-93.

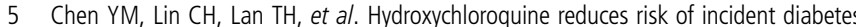
mellitus in lupus patients in a dose-dependent manner: a population-based cohort study. Rheumatology (Oxford) 2015:54:1244-9. 